\title{
Evidence of enzootic circulation of West Nile virus (Nea Santa-Greece-2010, lineage 2), Greece, May to July 2011
}

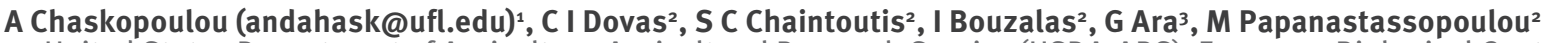

1. United States Department of Agriculture-Agricultural Research Service (USDA-ARS), European Biological Control Laboratory, Thessaloniki, Greece

2. Aristotle University of Thessaloniki, Faculty of Veterinary Medicine, Laboratory of Microbiology and Infectious Diseases, Thessaloniki, Greece

3. American Farm School, Thessaloniki, Greece

Citation style for this article:

Chaskopoulou A, Dovas CI, Chaintoutis SC, Bouzalas I, Ara G, Papanastassopoulou M. Evidence of enzootic circulation of West Nile virus (Nea Santa-Greece-2010, lineage 2), Greece, May to July 2011.

Euro Surveill. 2011;16(31):pii=19933. Available online: http://www.eurosurveillance.org/ViewArticle.aspx?Articleld=19933

Article published on 4 August 2011

A West Nile virus (WNV) surveillance network including sentinel chickens was deployed in Thessaloniki county, Greece, from May to July 2011. For the first time in summer 2011, a chicken WNV isolate from 6 July was molecularly identified. The partial NS3 sequence was identical to that of the Nea Santa-Greece-2010 WNV lineage 2, detected in central Macedonia in 2010. This suggests that WNV is actively circulating in central Macedonia and that it may have overwintered in northern Greece.

During 2010, Greece underwent the second largest West Nile virus (WNV) epidemic in Europe in the last two decades with 262 clinical human cases and 35 fatalities [1]. WNV lineage 2 was identified in two pools of Culex mosquitoes (Nea Santa-Greece-2010 virus) [2] and in wild birds [3] that were sampled during the epidemic season of 2010 from areas in close proximity to human cases.

No active vector and arbovirus surveillance system was in place in Greece before the epidemic in 2010. We initiated a monitoring programme in 2011, from May to November, in order to understand subsequent transmission, to document virus activity, and to better assess the relative importance of vector species. A small scale mosquito and animal surveillance network was established in the county of Thessaloniki, one of the areas with the highest number of human cases during the epidemic of 2010 [1]. The long term objective of this project is to design within the following years an optimum, large scale arbovirus surveillance programme for Thessaloniki. We report here preliminary findings of the study that will have interest for public health authorities.

\section{Methods}

\section{Sentinel chickens}

Six chicken flocks (six chickens per flock) were placed in stationary cages along the western and eastern edges of Thessaloniki (three flocks on each side) to monitor WNV activity in areas suitable for potential enzootic transmission [4] (Figure 1). These areas combine abundance of mosquito larval sites (e.g. rice fields) and potential habitat for migratory birds (e.g. Axios River delta) that may serve as reservoir populations for WNV. The flocks were placed within or in close proximity to residential communities that experienced abundant mosquito activity. All chickens were confirmed WNV antibody negative prior to placement in the field. For each flock, the chicken cage was divided in six compartments so that each chicken would be kept separate from the others. Chickens were bled through the ulnar vein weekly (about $1 \mathrm{ml}$ of blood sample per chicken).

\section{Mosquito population monitoring}

Carbon-dioxide (dry ice) baited Centers for Disease Control (CDC) light traps (John W. Hock, Gainesville, United States (USA)) were deployed once a week at 28 sites in the Thessaloniki area beginning 20 May 2011 (Figure 1). Traps were located at approximately equal intervals in order to provide a geographically representative sampling.

\section{Laboratory analysis}

Chicken plasma $(0.5 \mathrm{ml})$ and sera $(0.25 \mathrm{ml})$ were collected for virus detection and serology, respectively. Serum samples were tested by ELISA for the detection of WNV-specific antibodies using a commercial ELISA kit (ID Screen West Nile Competition, IDVET, France). After the detection of seroconversion, RNA was extracted from selected plasma samples previously taken from the seroconverted birds. RNA extracts were examined using a one tube RT-PCR screening protocol employing a primer pair (WNPolUp: 5'-TTTTGGGAGATGGTGGATGARGA-3' and WNPolDo2: 5'-CCACATGAACCAWATGGCTCTGC-3') designed for the specific detection of WNV and targeting a $144 \mathrm{bp}$ part of the nonstructural protein 5 (NS5) gene. Samples found positive by the RT-PCR screening protocol, were additionally subjected to RNA reverse transcription using random hexamers, followed by two PCR assays employing a primer pair (WN-NS3up1: 5'-GCTGGCTTCGAACCTGAAATGTTG-3' 
and WN-NS3do1: 5'-CAATGATGGTGGGTTTCACGCT-3') targeting a 778 bp part of the nonstructural protein 3 (NS3) gene, and a nested primer pair (WN-NS3up2: 5'-GCAAGATACTTCCCCAAATCATCAAGG-3' and WN-NS3do2: 5'-TGTCTGGGATCTCTGTTTGCATGTC-3') targeting a respective $423 \mathrm{bp}$ part. The nested PCR products were bidirectionally sequenced. The NS3 gene was selected for molecular characterisation because it is phylogenetically informative [5] and it encodes a protein residue (NS3-249) subject to adaptive evolution leading to increased viremia potential and virulence [6].

\section{Results}

Seroconversion of the first sentinel chicken was detected in the agricultural area of west Thessaloniki in the city of Chalastra $\left(40^{\circ} 37^{\prime} 37.27^{\prime \prime} \mathrm{N}, 22^{\circ} 43^{\prime} 45.05\right.$ " E) (Figure 1) on 29 June. On 13 July a second chicken seroconversion was detected in the city of Agios Athanasios

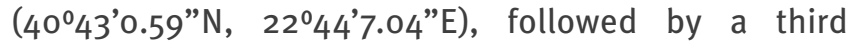
chicken seroconversion on 20 July in the same area.

All prior samples collected from the three seroconverted chickens were tested using the one tube
RT-PCR screening protocol targeting NS5. All RNA samples were negative except in the case of the sentinel chicken in the city of Agios Athanasios (4043'0.59"N, $22^{\circ} 44^{\prime} 7.04$ "E) which seroconverted on 13 July. More specifically, a band of expected size was obtained from one PCR product derived from a sample taken from that respective chicken, one week before seroconversion (6 July). The specific RNA extract was subjected to nested PCR, targeting the partial NS3 gene sequence, which was subsequently determined. The sequence was deposited in GenBank database under accession number JN398476 and according to BLAST algorithm, it presented highest nucleotide sequence identity (99.73\%) to that from Nea Santa-Greece-2010 virus derived from a Culex mosquito pool tested during the 2010 epidemic in Central Macedonia [7]. The inferred partial NS3 amino acid sequence was $100 \%$ identical to that of the Nea Santa-Greece-2010 WNV lineage 2. As in the Nea Santa-Greece-2010 virus NS3 sequence, the inferred NS3 residue 249 was determined to be proline, similar to several neuroinvasive lineage 1 WNV strains [6]. In contrast, all other investigated lineage 2 viruses have a NS3 protein with a histidine at this position [7].

\section{FIGURE 1}

Location of mosquito traps $(n=28)$ and sentinel chicken flocks $(n=6)$ for West Nile virus surveillance, Thessaloniki county, Greece, 2011

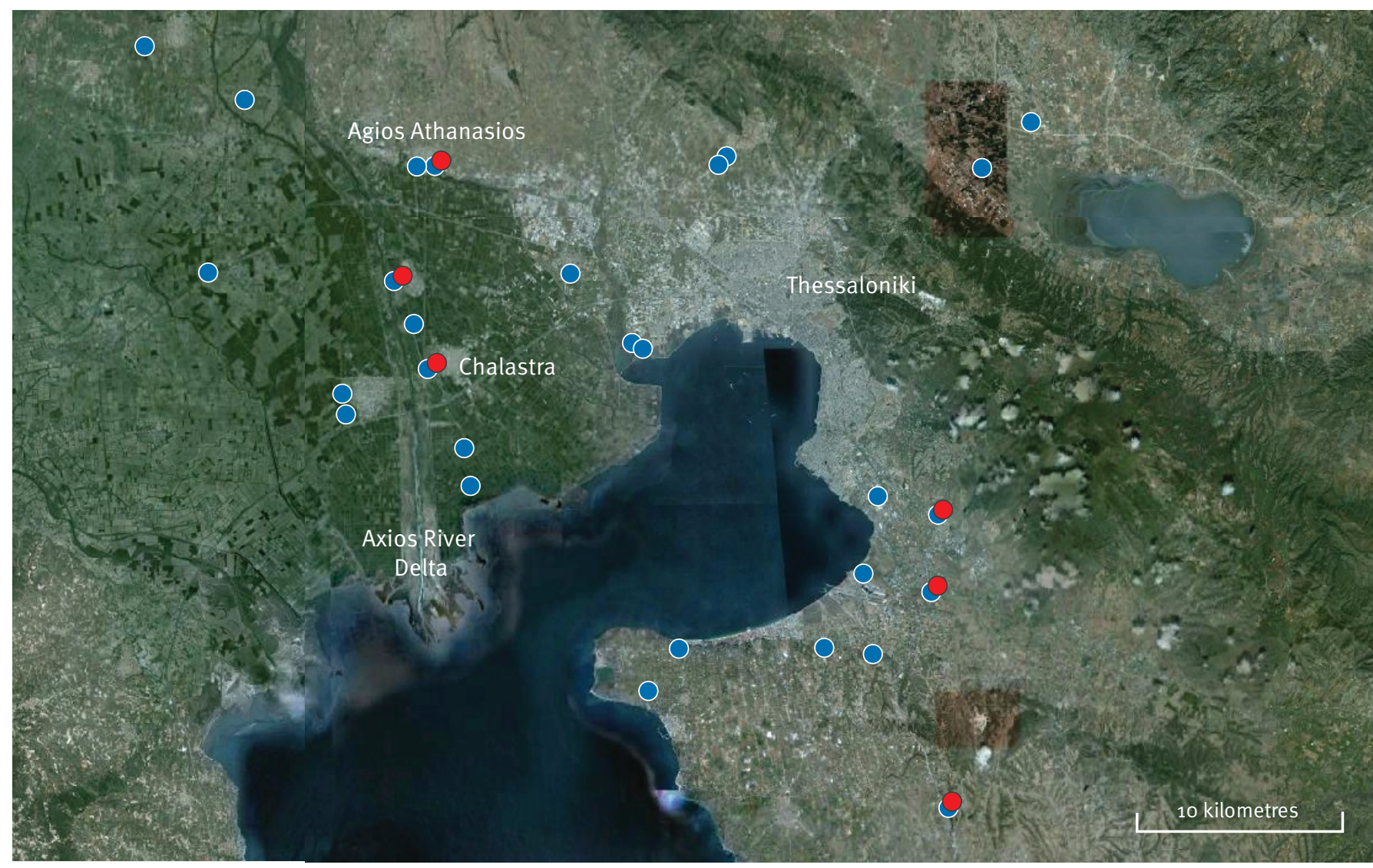

Mosquito trap location

Chicken flock location (collocated with mosquito trap)

Agios Athanasios and Chlalastra are the two cities where enzootic circulation of the virus was detected. 
The cumulative number of Culex mosquitoes trapped weekly in the agricultural area of Thessaloniki (Figure 2) was low $(n=142)$ during the last week of May and the first two weeks of June. The population rapidly increased during the second half of June, with a peak $(n=23,867)$ at the end of the month. During the following two weeks, the population decreased and then started building up again during the third week of July. So far, the most prevalent mosquito species in both residential and agricultural areas (rice-fields) were Culex pipiens followed by Culex modestus Ficalbi. It should be noted that $C$. modestus populations started building up significantly in early July. Testing for WNV in mosquitoes is in progress but no results are available at this stage of the surveillance programme.

\section{Discussion}

This is the first report of enzootic circulation of WNV Nea Santa-Greece-2010 in Greece during 2011, one year after the WNV epidemic in Greece. The virus in 2010 was detected in Nea Santa from a Culex mosquito pool [2], and in 2011 we detected an identical isolate (molecular characterization based on NS3 gene) in the agricultural area of west Thessaloniki in the city of Agios Athanasios, approximately $21 \mathrm{~km}$ southwest of Nea Santa. The 2011 Greek WNV isolate shows close genetic relationship to the lineage 2 goshhawk-Hungary-2004 strain that emerged in Hungary in 2004 but differs from the latter in that it maintains the amino acid substitution $\mathrm{H}_{249} \mathrm{P}$ found in the Nea Santa-Greece-2010 isolate, which may be associated with increased virulence [7]. WNV lineage 1 strains are distributed in north Africa, Europe, America, Asia and Australia, whereas lineage 2 are mostly distributed in south Africa and Madagascar. Due to increased illness and death caused by WNV lineage 1 compared to lineage 2 in the past, lineage 2 strains were previously considered to be less virulent. However, recent evidence from Africa and Hungary demonstrated that lineage 2 strains may also result in severe disease $[8,9]$.

Up to now, no WNV genomic sequences have been published from the human cases during the 2010 epidemic and there is no direct evidence to incriminate the WNV Nea Santa-Greece-2010 strain as the cause of the 2010 human epidemic. The discovery of the same strain in sentinel chickens in 2011 suggests that the virus was able to overwinter in this region, consistent with current opinion on the endemicity of WNV in Europe [10]. Specifically, the reoccurrence of WNV in continuous years in the same places in Romania and Italy, involving humans and equines, is likely linked to the endemicity of the infection in the areas rather than to a new introduction of the virus [10]. This situation appears to parallel that experienced in California, USA, which has a similar climate (warm temperate, seasonal winter rainfall) [11], where WNV was introduced in 2003, quickly spread throughout the state, and became endemic with the ability to overwinter in a cycle between winter mosquitoes and birds.
Transmission in the sentinel chickens occurred immediately after the first significant Culex population peak, as has been observed in WNV outbreaks [11,12]. Two of the principal WNV vectors in Europe, C. pipiens and $C$. modestus [13], are highly abundant in the agricultural area of Thessaloniki and both species may be associated with the transmission of the virus. In Greece, so far, the virus has been isolated from two pools of $C$. pipiens mosquitoes during the epidemic of 2010 [2]. More studies are needed to increase our knowledge on the role of the aforementioned species in the enzootic, epizootic and tangential (e.g. to humans) transmission of WNV in Greece.

Monitoring disease activity by using sentinel animals can provide critical information regarding periods of increased transmission. Surveillance networks involving sentinel animals and mosquitoes have been used in many parts of the world as an early warning system aiming to identify periods and locations of elevated risk of WNV disease transmission $[14,15,16]$. The rationale behind these surveillance networks is (i) to increase our understanding of the epidemiology of arboviruses, (ii) to identify the circumstances favourable to the appearance of the disease in humans before this occurs, and (iii) to guide mosquito control efforts in time and space to reduce the impact or likelihood of an epidemic.

Arbovirus surveillance systems can be expensive and labour intensive, with weekly monitoring of chickens. This is nevertheless feasible and these systems have been successfully established in some regions [16]. In urban centres of increased vulnerability to mosquito

\section{FIGURE 2}

Culex female mosquito abundance in the agricultural area of west Thessaloniki, Greece, $2011(\mathrm{n}=74,909)$

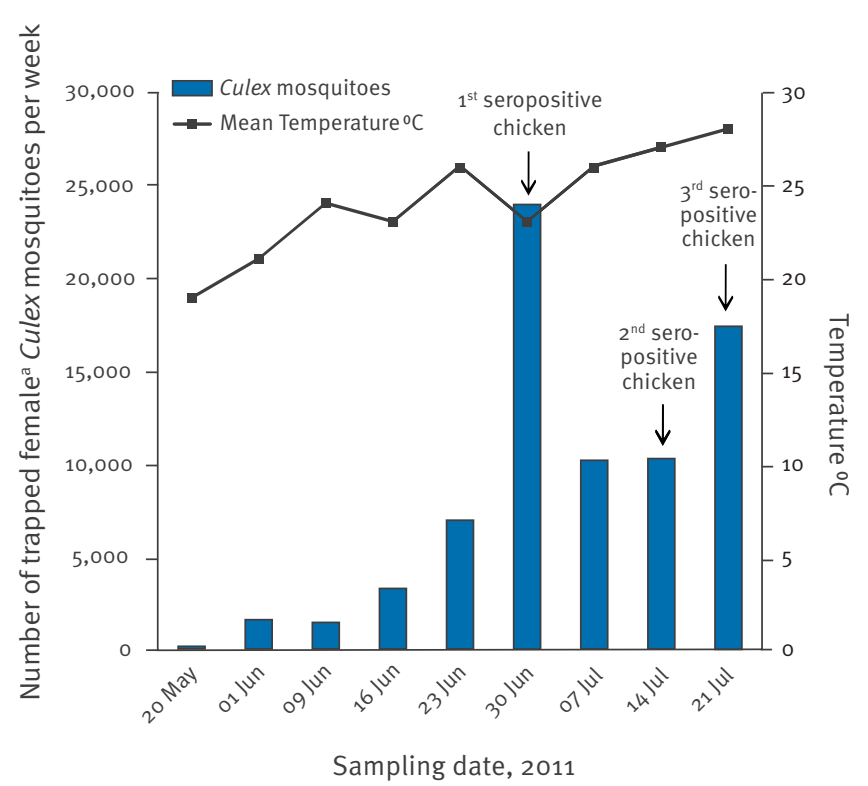

a Female mosquitoes were targeted by mosquito traps and accidental male mosquito collection was negligible («0.1\%). 
borne epidemics, such as Thessaloniki (approximately 1 million inhabitants, in close proximity to prolific mosquito breeding environments), there is a need and demand for such systems and the benefits associated with their successful deployment outweigh the associated costs. This is the first active arbovirus surveillance system in place in Thessaloniki and in order to optimise its use, extensive data are required in the following years. These data could help create a useful disease surveillance tool that may increase our understanding of the disease transmission cycle and help the local authorities to design a local WNV response plan based on the disease transmission levels. It is encouraging, that through a small scale surveillance system, like the one described in this paper, we were able to detect WNV enzootic circulation in Greece before the onset of any human cases for the year of 2011.

\section{Acknowledgements}

This project is funded by the Mosquito Control Programme Contract of Thessaloniki County. The Development Agency of Thessaloniki (ANETH) is the implementation body of the programme and the funding is provided by the Greek government, the Regional Authority of Central Macedonia, the Local Union of Communities and Municipalities of Thessaloniki County (TEDK) and the eight municipalities of Thessaloniki County. We also thank all the residents of the Thessaloniki region who kindly accepted to host the sentinel chickens for the duration of the study. Most importantly, we thank the field technical team Nikos Kampragkos and Aristeidis Kampragkos for their excellent cooperation.

\section{References}

1. Hellenic Center for Disease Control and Prevention (HCDC) Report on West Nile Virus Epidemic, 2010. [Accessed 27 Jul 2011]. Greek. Available from: http://www.keelpno.gr/images/ stories/keelpno/ios_ditikou_neilou/ekthesi_epidimias_2010_ revised.pdf

2. Papa A, Xanthopoulou K, Gewehr S, Mourelatos S. Detection of West Nile virus lineage 2 in mosquitoes during a human outbreak in Greece. Clin Microbiol Infect. 2011; 17(8):1176-80.

3. Valiakos G, Touloudi A, lacovakis C, Athanasiou L, Bitsas P, Spyrou V, et al. Molecular detection and phylogenetic analysis of West Nile virus lineage 2 in sedentary wild birds (Eurasian magpie), Greece, 2010. Euro Surveill. 2011; 16(18):pii=19862. Available from: http://www.eurosurveillance.org/ViewArticle. aspx?Articleld $=19862$

4. Komar N. West Nile virus surveillance using sentinel birds. Ann N Y Acad Sci. 2001; 951:58-73.

5. Gray RR, Veras NMC, Santos LA, Salemi M. Evolutionary characterization of the West Nile Virus complete genome. Mol Phylogenet Evol. 2010; 56(1):195-200.

6. Brault AC, Huang CY, Langevin SA, Kinney RM, Bowen RA, Ramey WN, et al. A single positively selected West Nile viral mutation confers increased virogenesis in American crows. Nat Genet. 2007; 39(9):1162-6.

7. Papa A, Bakonyi T, Xanthopoulou K, Vasquez A, Tenorio A Nowotny N. Genetic characterization of West Nile virus lineage 2, Greece, 2010. Emerg Infect Dis. 2011; 17(5):920-2.

8. Murgue B, Zeller H, Deubel V. The ecology and epidemiology of West Nile virus in Africa, Europe and Asia. Curr Top Microbiol Immunol. 2002; 267:195-221.

9. Erdelyi K, Ursu K, Ferenczi E, Szeredi L, Ratz F, Skare J, et al. Clinical and pathologic features of lineage 2 West Nile virus infections in birds of prey in Hungary. Vector Borne Zoonotic Dis. 2007; 7(2):181-188

10. Calistri P, Giovannini A, Hubalek Z, Ionescu A, Monaco F, Savini G, et al. Epidemiology of west nile in europe and in the mediterranean basin. Open Virol J. 2010; 4:29-37.
11. Reisen W, Lothrop H, Chiles R, Madon M, Cossen C, Woods $\mathrm{L}$, et al. West Nile virus in California. Emerg Infect Dis. 2004; 10(8):1369-78.

12. Sacramento-Yolo Mosquito and Vector Control District. Annual Report, 2006. [Accessed 26 Jul 2011]. Available from: http://www.fightthebite.net/download/annualreport/ AnnualReport2006.pdf

13. Hubalek Z, Halouzka J. West Nile fever - a reemerging mosquito-borne viral disease in Europe. Emerg Infect Dis. 1999; 5(5):643-50.

14. Cernescu C, Nedelcu N, Tardei G, Ruta S, Tsai TF. Continued transmission of West Nile virus to humans in southeastern Romania, 1997-1998. Infect Dis. 2000; 181(2):710-2.

15. Gubler DJ, Petersen LR, Roehrig JT, Campbell GL, M.D., Ph.D.Komar N, Nasci RS et al. Epidemic/Epizootic West Nile Virus in the United States: Guidelines for Surveillance, Prevention, and Control. Centers of Disease Control and Prevention; 2003. [Accessed 26 Jul 2011]. Available from: http://www.cdc.gov/ncidod/dvbid/westnile/resources/wnvguidelines-aug-2003.pdf

16. Connelly CR, Carlson DB, editors. 2009. Florida Coordinating Council on mosquito control. Florida mosquito control: The state of the mission as defined by mosquito controllers, regulators, and environmental managers. Vero Beach, Florida: University of Florida, Institute of Food and Agricultural Sciences, Florida Medical Entomology Laboratory. [Accessed 25 Jul 2011]. Available from: http://mosquito.ifas.ufl.edu/ Documents/Florida_Mosquito_Control_White_Paper.pdf 